\title{
Effects of temperature and genetic stress on life history and fluctuating wing asymmetry in Culex pipiens mosquitoes
}

\author{
Mandla MPHO, Amanda Callaghan and Graham J. HOLlOWAY* \\ Division of Zoology, School of Animal \& Microbial Sciences, The University of Reading, Whiteknights, PO Box 228, \\ Reading RG6 6AJ, UK
}

Key words. Fluctuating asymmetry, inbreeding, organophosphate resistance, environmental stress, Culex pipiens, biomonitor

\begin{abstract}
Fluctuating asymmetry (FA) of bilaterally symmetrical organisms has been introduced as a promising indicator of environmental stress. Stress factors reported to contribute to developmental stability include inbreeding and the presence of resistance genes. In the current study we examined the effect of stress derived from high developmental temperatures, resistance genes and low genetic variation on life history variables and wing FA in Culex pipiens mosquitoes. Three strains were compared: two inbred laboratory strains sharing a similar genetic background but differing in that one strain contained organophosphate (OP) resistance genes, and a third strain that was an outbred OP resistant field strain recently collected from India. There were no strong and general trends that suggested that the OP resistant lab strain was less fit than the OP susceptible strain, although there were some specific among strain differences for some treatments. Fluctuating asymmetry (FA) of wing traits was higher in the laboratory strains than the field strain, suggesting that inbreeding may cause elevated FA in the study species. There was no evidence that the resistance genes were associated with increased wing FA. Wing FA increased with increasing developmental temperature in females, but the association was less strong in males. There was a significant difference between the sexes in this respect. The results are discussed with reference to the value of FA as a biomonitor of environmental stress.
\end{abstract}

\section{INTRODUCTION}

Fluctuating asymmetry (FA), the random nondirectional deviation from perfect bilaterally symmetry, is commonly used as a measure of stress during development. It is usually assumed that elevated levels of FA are the result of environmental and/or genetic stress experienced by the organism during ontogeny which perturbs the normal developmental programme (Van Valen, 1962; Palmer \& Strobeck, 1986; Palmer, 1994; Markow, 1995). Elevated levels of FA have been associated with environmental variables such as temperature, pollution, parasites etc., and also genetic factors such as insecticide resistance and increased levels of homozygosity (reviewed in Allendorf \& Leary, 1986; Palmer \& Strobeck, 1986). As such, it has been proposed as a general tool for biomonitoring stress within populations regardless of the nature of stress. However, there are also many reports of studies that have failed to find any association between FA and environmental stress (e.g. Rabitsch, 1997; Dobrin \& Corkum, 1999; Bjorksten et al., 2000; Mpho et al., 2000) or genetic stress (Møller, 1992; Fowler \& Whitlock, 1994; Hunt \& Simmons, 1997; Sheridan \& Pomiankowski, 1997; Woods et al., 1998; Floate \& Fox, 2002). The disproportional representation of positive to negative association in the literature could be because many negative results are not reported or published.

This study investigated the use of FA as a general tool for monitoring stress using the mosquito Culex pipiens as a model. Two main stressors were investigated: Temperature and the presence of insecticide resistance genes. Stress through inbreeding, although not part of the inves- tigation per se, could also be inferred from a comparison of inbred laboratory strains with an outbred field strain.

Mosquitoes as ectotherms are greatly influenced by ambient temperature (Atkinson, 1994). Temperature is a crucial variable on which their survival depends since it influences immature developmental rate as well as maturation processes, mating and oviposition rates in adults. Most insects predominantly operate optimally within a narrow range of temperatures. Deviations from this range could impose stress during development (Imasheva et al.,1997) which may lead to increased levels of developmental instability (Parsons, 1989, 1990; McKenzie \& Yen, 1995; Hoffmann \& Parsons, 1997; Imasheva et al., 1997; Savage \& Hogarth, 1999). However, morphological, physiological and behavioural traits can exhibit phenotypic plasticity in response to rearing temperature. The phenotypic variation of a trait could be influenced by environmental variations, an interaction between the environment and the genotype or just wholly genetic expression (Anderson, 1973). A plastic response might enable an organism to adapt to the prevailing environmental conditions and adjust its resources accordingly (Atkinson, 1994).

Many insects and other organisms have developed resistance to insecticides as an adaptation to toxic environments. Whether insecticides induce resistance or just act as a selective agent to the pre-existing variation is still a matter of debate (McKenzie, 1996). However, what remains is that resistance has fitness costs associated with it such as reduced fecundity, fertility or survival and reduced developmental stability (Ferrari \& Georghiou,

\footnotetext{
* Corresponding author. E-mail: g.j.holloway@reading.ac.uk; tel.: 0118931 8013; fax.: 01189310180.
} 
1981; El-Khatib \& Georghiou, 1985; McKenzie \& Batterham, 1994). A mosquito model system is suitable for the study of the effects of resistance genes on developmental stability since well-studied resistance genes are available. The organophosphate pesticide resistance genes in this study are overexpressed carboxylesterases which bind to and sequester the pesticide (Cuany et al., 1993). Overexpression is at least partly due to the presence of multiple copies of the structural genes coding for the esterases (Mouchès et al., 1986, Guillemaud et al., 1997).

The purpose of the present study was to investigate the effect of stress, induced both environmentally and genetically, on fitness characters and fluctuating asymmetry in C. pipiens. Both laboratory insecticide susceptible and resistant strains were used in addition to a resistant field strain.

\section{MATERIALS AND METHODS}

\section{Mosquito strains}

S-LAB is the standard laboratory insecticide susceptible strain that has been reared continually in the laboratory without exposure to insecticides (Georghiou et al., 1966). TEMIX is an OP resistant laboratory strain that was obtained by crossing S-LAB with TEM-R; TEM-R is resistant to temephos due to overproduction of insecticide binding B1 esterases (Georghiou et al., 1975). Reciprocal crosses of the parental strains produced an F1 that was repeatedly backcrossed to S-LAB for seven generations to produce progeny with a common genetic background to S-LAB. The TEMIX strain was then recovered by selection of the larvae at the fourth instar larval stage with the OP insecticide temephos. Single pair families were then established and the resulting progeny were tested for high esterase activity using the method of Pasteur \& Georghiou (1989). Only those families that produced resistant genotypes were kept by selecting every generation with an $\mathrm{LC}_{80}$ of temephos insecticide. The selection pressure was maintained for two years. KOTTA was collected in 1999 from the field as egg rafts from a filariasis endemic area of India where it had been constantly exposed to insecticides such as organophosphates, pyrethroids and carbamates. KOTTA was resistant to temephos due to the overproduction of insecticide binding A2B2 esterases (V.R. James pers. comm.). To minimise any potential loss of genetic variation KOTTA was bred under laboratory conditions for just one generation prior to the experimentation reported here.

\section{Insecticide exposure}

Bioassays were carried out in $250 \mathrm{ml}$ plastic bowls to which $100 \mu \mathrm{L}$ of temephos in ethanol was added to $99.9 \mathrm{ml}$ distilled water to make up to the desired concentration. There were a total of four replicates per insecticide concentration tested and per control. In the control, $100 \mu \mathrm{L}$ of ethanol was added to the water. For each test, 25 early fourth instar larvae were used to avoid pupation during the test. After $24 \mathrm{hr}$, the mortality was recorded. Mortality was corrected using the Abbott's formula to account for the natural mortality not related to the test response (Abbott, 1925) and then converted to probits (Finney, 1971). The Micro Probit ${ }^{\circ}$ program (Probit Version 1.5, USEPA, Ohio, USA) was used for the bioassay dose response analysis.

\section{Temperature effects on life history}

Eggs from each strain were hatched at $25^{\circ} \mathrm{C}$ and $85 \%$ relative humidity in plastic rearing trays $(35 \mathrm{~cm} \times 24 \mathrm{~cm} \times 5 \mathrm{~cm})$ containing $1.5 \mathrm{~L}$ of tap water. Fish food (Trouw, UK limited) was used as the standard larval diet. Six replicates of 30 second- instar individuals per strain were placed in $100 \mathrm{ml}$ of tap water in plastic cups and raised until adult eclosion at one of the three temperatures: $25^{\circ} \mathrm{C}, 30^{\circ} \mathrm{C}$ or $37^{\circ} \mathrm{C}$. Water was changed every other day and fresh food was provided following each water change. To avoid temperature fluctuations following water change, water that had been allowed to equilibrate at the appropriate temperature was used for each water change. Development time, pupation, mortality and adult emergence were recorded daily. Pupae were isolated daily into separate cups for adult eclosion. The daily adult emergents were placed in sample tubes and stored in a $-20^{\circ} \mathrm{C}$ freezer for subsequent analysis. Frozen adults were placed in an oven at $95^{\circ} \mathrm{C}$ for 5 hours to dry (Lang, 1963). Adults were then weighed on a Cahn 29 Automatic Electrobalance to an accuracy of $\pm 0.001 \mathrm{mg}$. Data were analysed by ANOVA using Minitab for Windows.

\section{Measurement of wing morphological characters and FA}

The measurement of wing morphological characters and FA were conducted as detailed in Mpho et al. (2000). Briefly, wing images were captured using a Moritex MS-500 m-Scopeman ${ }^{\mathbb{E}}$ and a Data Translation DT2255 Quick Capture Board. Images were analysed using NIH image software (version 1.52). Four metric characters were measured: wing length (WL), measured as the linear distance from the distal end of the alula to the peripheral tip of the $R_{3}$ vein, D6: The linear distance from the junction of the radio-medial cross vein and medial vein to the peripheral tip of the $R_{4+5}$ vein, D8: The linear distance from the junction of the radio-medial cross vein and medial vein to the peripheral tip of the $\mathrm{R}_{2}$ vein, and wing area (WA): The surface area of the wing (excluding the fringe) to the bend of the trailing edge of the alula and joining the subcosta with a perpendicular line. See Mpho et al. (2000) for further details. All linear and area measurements were measured to an accuracy of $0.01 \mathrm{~mm}$ and $0.01 \mathrm{~mm}^{2}$, respectively. All character size estimates were the average of four measurements with two separate mountings. One-way ANOVAs were used for checking measurement errors.

Two FA indices are presented: FA1 and FA10. FA1 is the mean average absolute difference between the sides and FA10 is the variance between sides after accounting for the measurement error (Palmer, 1994). To test for differences in trait FA1 between treatment effects, Levene's test of variance heterogeneity was used on individual absolute differences between sides $\left(\left|R_{i}-L_{i}\right|\right)$. All statistical tests were performed using Minitab for Windows (Minitab Inc., 1995) and Palmer's spreadsheet (Palmer \& Strobeck, 1986; Palmer, 1994).

The $F$-ratio tests whether the true FA variance is statistical significant relative to the measurement error (David et al., 1999). FA variances were tested for normality by plotting normal probability plots and $t$-tests were used to check whether they were centred on the mean of zero (Swaddle et al., 1994). Trait size was regressed against the absolute asymmetry. The absolute asymmetry was also regressed against body size to check whether FA covaried with body size. No association between FA and size was detected and hence correction for size difference was not necessary.

\section{RESULTS}

\section{Bioassay analysis}

The bioassay results for S-LAB, TEMIX, and KOTTA are shown in Fig. 1. The resistance ratio at the $\mathrm{LC}_{50}$ for TEMIX (LC $\left.\mathrm{L}_{50} 0.197 \mathrm{mg} / \mathrm{L}\right)$ and KOTTA (LC $\mathrm{LC}_{50} 0.0277$ $\mathrm{mg} / \mathrm{L})$ strains were calculated as 224 and 32 fold, respectively, with reference to $\mathrm{S}-\mathrm{LAB}\left(\mathrm{LC}_{50} 0.00088 \mathrm{mg} / \mathrm{L}\right)$. 


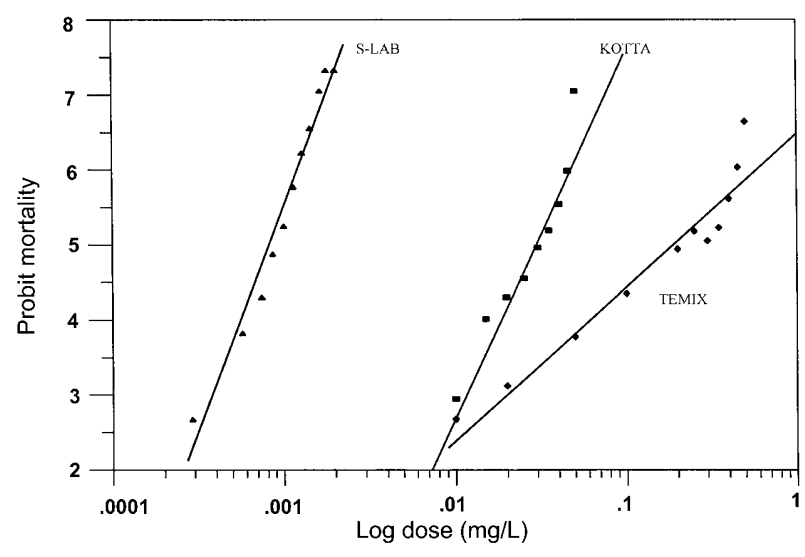

Fig. 1. Mortality response (probit transformed) of one field strain (KOTTA) and two laboratory strains (S-LAB and TEMIX) of Culex pipiens mosquitoes to varying doses (log. transformed) of the organophosphate insecticide temephos.

\section{Effects of temperature on life history}

There was a significant difference in the duration from second instar to adult emergence among strains $\left(F_{2,38}=\right.$ 98.96, $P<0.0001)$ and across temperatures $\left(F_{2,38}=\right.$ 172.47, $P<0.0001$ ) (Table 1$)$. There was a significant strain by temperature interaction effect $\left(F_{2,53}=8.60, P<\right.$ $0.001)$, indicating that some strains were affected by temperature more than others. KOTTA had the longest development time. A Tukey Honestly Significant Difference (HSD) comparison test of all mean development periods indicated significant differences between KOTTA and the other two strains. There was no difference in mean development time between S-LAB and TEMIX $\left(F_{2,25}=0.28, P\right.$ $=0.60$ ).

There was a significant difference in the adult survivorship among strains $\left(F_{2,39}=49.06, P<0.0001\right)$ and across temperatures $\left(F_{2,39}=56.60, P<0.0001\right)$. Development at $37^{\circ} \mathrm{C}$ resulted in high mortality with only $49 \%, 21 \%$ and $17 \%$ of adults emerging in KOTTA, S-LAB and TEMIX, respectively (Table 1$)$. There was a significant interaction between strain and temperature $\left(F_{4,39}=10.35, P<\right.$ $0.0001)$. TEMIX had the lowest survivals at all tempera- tures. Survival in S-LAB decreased with increase in temperature. However, KOTTA displayed significantly higher percentage emergence at $25^{\circ} \mathrm{C}$ and $30^{\circ} \mathrm{C}$, with the highest survival recorded at $30^{\circ} \mathrm{C}$ and the lowest at $37^{\circ} \mathrm{C}$.

There were significant weight differences among the three strains $\left(F_{2,873}=384.73, P<0.010\right)$ and across temperature treatments $\left(F_{2,873}=143.62, P<0.010\right)$, with KOTTA being the lightest. A comparison of the laboratory strains S-LAB and TEMIX revealed a difference in weight at all three developmental temperatures in both males and females. TEMIX was the heavier of the two at $25^{\circ} \mathrm{C}$ in both males $\left(F_{1,102}=5.88, P=0.017\right)$ and females $\left(F_{1,83}=5.28, P=0.024\right)$. However, at $30^{\circ} \mathrm{C}$ and $37^{\circ} \mathrm{C}$ S-LAB was significantly heavier than TEMIX in both sexes $(P<0.001$ in each case) (Table 1$)$. KOTTA was significantly heavier at $30^{\circ} \mathrm{C}$ in both sexes than at the other two temperatures.

General linear modelling (GLM) was used to compare wing sizes of the three strains. There was a significant strain, sex and temperature effect on wing size (strain: $F_{2,658}=124.43, P<0.001$; sex: $F_{1,658}=1081.51, P<$ 0.001 ; temperature: $\left.F_{2,658}=247.25, P<0.001\right)$. There were significant temperature effects $(P<0.001)$ on all traits in all strains. The wing trait size of both females and males decreased as temperature increased.

\section{Fluctuating asymmetry analysis}

Tables 2 and 3 show the FA1 and FA10 values for wing characters measured in female and male mosquitoes, respectively. Measurable amounts of FA were detected in the various characters measured. FA was highest for wing area varying mostly between $2 \%$ and $3 \%$. For the other three characters, FA rarely exceeded $1 \%$, although mean values exceeded $1 \%$ for wing length and D8 in S-LAB and TEMIX females. For all characters analysed, nondirectional variance was significantly greater than measurement error and none of the character distributions were skewed with a mean deviating significantly from zero, in other words displayed directional asymmetry. The character WA was not included in the FA analysis because the measurement error was high. None of the wing character

TABLE 1. Mean \pm SE of life history parameters for field (KOTTA) and laboratory (TEMIX and S-LAB) strains of Culex pipiens mosquitoes reared at three temperatures.

\begin{tabular}{|c|c|c|c|c|c|}
\hline & \multicolumn{2}{|c|}{ Number of days to } & \multirow[t]{2}{*}{ Egg to adult survival (\%) } & \multicolumn{2}{|c|}{ Dry adult weight (mg) } \\
\hline & Pupation & Adult emergence & & Female & Male \\
\hline \multicolumn{6}{|l|}{$25^{\circ} \mathrm{C}$} \\
\hline KOTTA & $19.97 \pm 0.226$ & $21.72 \pm 0.277$ & $83.83 \pm 4.00$ & $0.386 \pm 0.0117$ & $0.298 \pm 0.0209$ \\
\hline TEMIX & $16.63 \pm 0.687$ & $19.34 \pm 0.644$ & $48.33 \pm 3.52$ & $0.620 \pm 0.0170$ & $0.476 \pm 0.0102$ \\
\hline S-LAB & $17.63 \pm 0.130$ & $20.06 \pm 0.160$ & $90.00 \pm 3.33$ & $0.577 \pm 0.0093$ & $0.447 \pm 0.0098$ \\
\hline \multicolumn{6}{|l|}{$30^{\circ} \mathrm{C}$} \\
\hline KOTTA & $16.40 \pm 0.200$ & $18.33 \pm 0.191$ & $94.45 \pm 2.68$ & $0.464 \pm 0.0298$ & $0.236 \pm 0.0118$ \\
\hline TEMIX & $13.66 \pm 0.757$ & $14.55 \pm 0.653$ & $50.56 \pm 5.54$ & $0.559 \pm 0.0043$ & $0.398 \pm 0.0102$ \\
\hline S-LAB & $14.62 \pm 0.315$ & $16.50 \pm 0.204$ & $52.50 \pm 3.16$ & $0.692 \pm 0.0219$ & $0.529 \pm 0.0396$ \\
\hline \multicolumn{6}{|l|}{$37^{\circ} \mathrm{C}$} \\
\hline KOTTA & $14.52 \pm 0.337$ & $16.23 \pm 0.422$ & $48.67 \pm 5.41$ & $0.342 \pm 0.0145$ & $0.201 \pm 0.0051$ \\
\hline TEMIX & $12.75 \pm 0.495$ & $14.22 \pm 0.361$ & $16.67 \pm 4.04$ & $0.317 \pm 0.0154$ & $0.241 \pm 0.0257$ \\
\hline S-LAB & $10.83 \pm 0.167$ & $12.67 \pm 0.167$ & $20.83 \pm 11.42$ & $0.517 \pm 0.0178$ & $0.442 \pm 0.0590$ \\
\hline
\end{tabular}



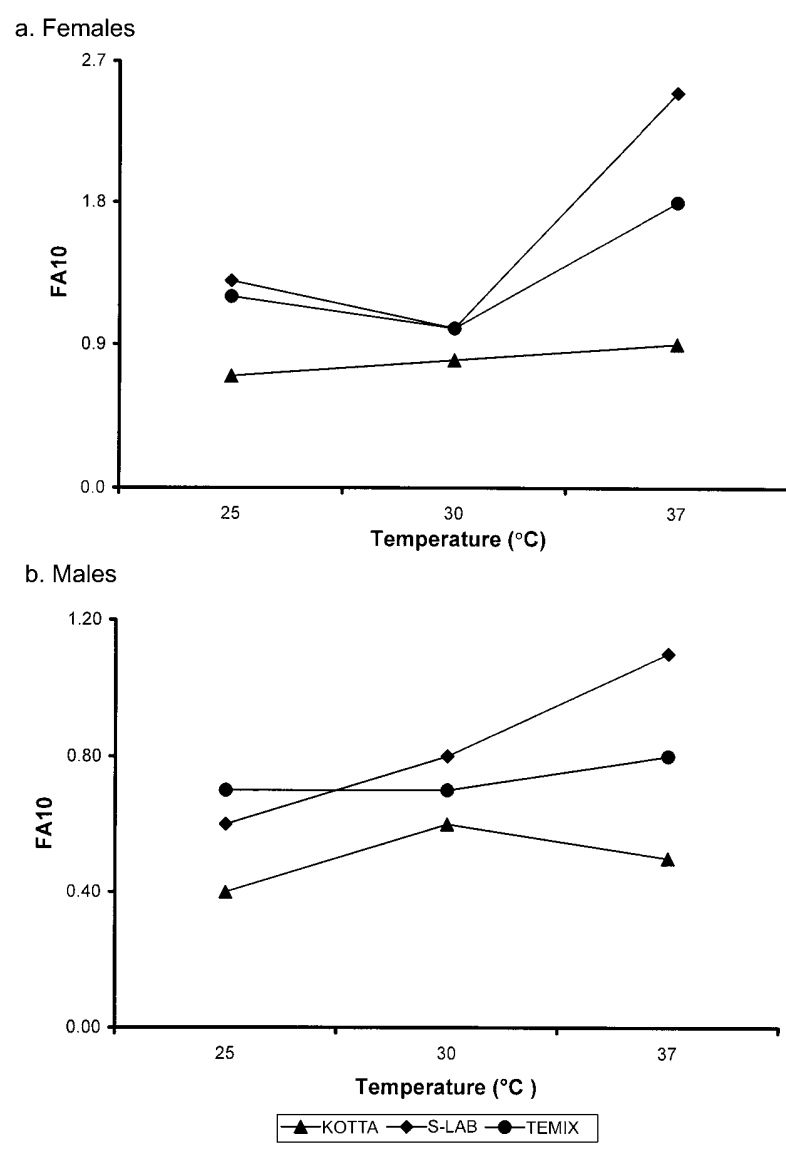

Fig. 2. Wing length FA10 values of a) females and b) males from one field strain ( $\boldsymbol{\Lambda}, \mathrm{KOTTA})$ and two laboratory strains ( $\bullet$, S-LAB and $\bullet$, TEMIX) of Culex pipiens mosquitoes after development at three different temperatures.

distributions displayed significant kurtosis, which would have provided evidence for anti-symmetry (Palmer, 1994). The level of FA10 observed at a given temperature for each strain paralleled the equivalent FA1 value. FA1 values are statistically analysed below. The level of significance of the difference between any pair of FA10 values in Tables 2 and 3 can be determined using the $F$ max-test for homogeneity of variances.

Anovas were used to analyse all variables (sex, strain and temperature). Females were generally more asymmetric (FA1) than males for WL $\left(F_{1,688}=15.29, P<\right.$ $0.0001)$ and $\mathrm{D} 6\left(F_{1,688}=4.65, P=0.031\right)$, but not D8 $\left(F_{1,688}=0.53, P=0.468\right)$. There was a highly significant strain effect on all three traits $(P<0.001$ in each case) with the laboratory strains showing higher FA10 than the field strain (Fig. 2). Females differed among strains in FA for all three morphometric wing traits $(P<0.001$ in each case) and again the laboratory strains had higher FA than the field strain. In males, $\mathrm{WL}\left(F_{2,315}=2.96, P=0.05\right)$ and D8 $\left(F_{2,315}=3.81, P=0.02\right)$ FA varied significantly among strains, whereas D6 FA did not $\left(F_{2,315}=3.81, P=0.912\right)$.

For the combined data set there was some evidence that temperature had an effect on female WL FA $\left(F_{2,361}=3.2\right.$, $\mathrm{P}=0.04)$ and male D8 FA $\left(\mathrm{F}_{2,315}=2.81, \mathrm{P}=0.06\right)$. S-LAB and TEMIX both responded to temperature stress with higher temperatures resulting in higher WL FA10 (Fig. 2). Figure 2 shows that at any given temperature, WL FA of the field strain KOTTA was lower than that of the laboratory strains (S-LAB and TEMIX) in both sexes (Fig. 2). WL FA in male S-LAB increased with increasing temperature, however the differences were not significant $\left(F_{\max 2,72}=2.09, \mathrm{P}=0.131\right)$.

\section{DISCUSSION}

Temperature is an important environmental variable that influences many developmental processes in organisms. For ectotherms, which rely primarily on external sources of heat, ambient temperature is crucial for survival (Atkinson, 1994; Sibly \& Atkinson, 1994; Atkinson \& Sibly, 1997). Our experimental results with Culex mos-

TABLE 2. FA1 and FA10 in wings of females of field (KOTTA) and laboratory (S-LAB and TEMIX) strains of Culex pipiens complex mosquitoes exposed to varying developmental temperatures. $\mathrm{WL}=$ wing length, $\mathrm{WA}=$ wing area, D6 and D8 are linear measurements within the wing (see text for details).

\begin{tabular}{|c|c|c|c|c|c|c|c|c|c|c|}
\hline \multirow[b]{2}{*}{ Strain } & \multirow[b]{2}{*}{ Trait } & \multicolumn{3}{|c|}{$25^{\circ} \mathrm{C}$} & \multicolumn{3}{|c|}{$30^{\circ} \mathrm{C}$} & \multicolumn{3}{|c|}{$37^{\circ} \mathrm{C}$} \\
\hline & & $\mathrm{n}$ & FA1 & FA10 & $\mathrm{n}$ & FA1 & FA10 & $\mathrm{n}$ & FA1 & FA10 \\
\hline KOTTA & WL & 51 & 0.00941 & 0.00007 & 50 & 0.01033 & 0.00008 & 63 & 0.01074 & 0.00009 \\
\hline KOTTA & D6 & 51 & 0.00673 & 0.00003 & 50 & 0.00840 & 0.00004 & 63 & 0.00709 & 0.00003 \\
\hline KOTTA & D8 & 51 & 0.00745 & 0.00004 & 50 & 0.00687 & 0.00002 & 63 & 0.00656 & 0.00003 \\
\hline KOTTA & WA & 51 & 0.02529 & 0.00040 & 50 & 0.02053 & 0.00031 & 63 & 0.01921 & 0.00023 \\
\hline SLAB & WL & 39 & 0.01440 & 0.00013 & 40 & 0.01230 & 0.00010 & 30 & 0.01880 & 0.00025 \\
\hline SLAB & D6 & 39 & 0.00900 & 0.00005 & 40 & 0.01200 & 0.00011 & 30 & 0.01250 & 0.00025 \\
\hline SLAB & D8 & 39 & 0.01310 & 0.0001 & 40 & 0.01000 & 0.00007 & 30 & 0.01130 & 0.00011 \\
\hline SLAB & WA & 39 & 0.02690 & 0.00039 & 40 & 0.03700 & 0.00099 & 30 & 0.04500 & 0.00107 \\
\hline TEMIX & WL & 31 & 0.01495 & 0.00012 & 41 & 0.01081 & 0.00010 & 31 & 0.01398 & 0.00018 \\
\hline TEMIX & D6 & 31 & 0.00828 & 0.00004 & 41 & 0.00837 & 0.00003 & 31 & 0.00828 & 0.00005 \\
\hline TEMIX & D8 & 31 & 0.01065 & 0.00006 & 41 & 0.00967 & 0.00006 & 31 & 0.00882 & 0.00007 \\
\hline TEMIX & WA & 31 & 0.003387 & 0.00076 & 41 & 0.02472 & 0.00036 & 31 & 0.02161 & 0.00036 \\
\hline
\end{tabular}


TABLE 3. FA1 and FA10 in wings of males of field (KOTTA) and laboratory (S-LAB and TEMIX) strains of Culex pipiens complex mosquitoes exposed to varying developmental temperatures. WL $=$ wing length, WA $=$ wing area, D6 and D8 are linear measurements within the wing (see text for details).

\begin{tabular}{|c|c|c|c|c|c|c|c|c|c|c|}
\hline \multirow[b]{2}{*}{ Strain } & \multirow[b]{2}{*}{ Trait } & \multicolumn{3}{|c|}{$25^{\circ} \mathrm{C}$} & \multicolumn{3}{|c|}{$30^{\circ} \mathrm{C}$} & \multicolumn{3}{|c|}{$37^{\circ} \mathrm{C}$} \\
\hline & & $\mathrm{n}$ & FA1 & FA10 & $\mathrm{n}$ & FA1 & FA10 & $\mathrm{n}$ & FA1 & FA10 \\
\hline KOTTA & WL & 49 & 0.00782 & 0.00004 & 61 & 0.00880 & 0.00006 & 34 & 0.00775 & 0.00005 \\
\hline KOTTA & D6 & 49 & 0.00823 & 0.00004 & 61 & 0.00672 & 0.00003 & 34 & 0.00627 & 0.00003 \\
\hline KOTTA & D8 & 49 & 0.00769 & 0.00003 & 61 & 0.00617 & 0.00002 & 34 & 0.00833 & 0.00005 \\
\hline KOTTA & WA & 49 & 0.01701 & 0.00013 & 61 & 0.01634 & 0.00020 & 34 & 0.01255 & 0.00009 \\
\hline S-LAB & WL & 32 & 0.00780 & 0.00006 & 30 & 0.01200 & 0.00008 & 30 & 0.01290 & 0.00011 \\
\hline S-LAB & D6 & 32 & 0.00870 & 0.00006 & 30 & 0.00600 & 0.00002 & 30 & 0.00710 & 0.00003 \\
\hline S-LAB & D8 & 32 & 0.00810 & 0.00006 & 30 & 0.00730 & 0.00005 & 30 & 0.01140 & 0.00008 \\
\hline S-LAB & WA & 32 & 0.02690 & 0.00049 & 30 & 0.04400 & 0.00126 & 30 & 0.01360 & 0.00024 \\
\hline TEMIX & WL & 42 & 0.01032 & 0.00007 & 32 & 0.00906 & 0.00007 & 31 & 0.01022 & 0.00008 \\
\hline TEMIX & D6 & 42 & 0.00698 & 0.00003 & 32 & 0.00646 & 0.00003 & 31 & 0.00860 & 0.00006 \\
\hline TEMIX & D8 & 42 & 0.00921 & 0.00004 & 32 & 0.00865 & 0.00005 & 31 & 0.01032 & 0.00009 \\
\hline TEMIX & WA & 42 & 0.02294 & 0.00039 & 32 & 0.02052 & 0.00027 & 31 & 0.01710 & 0.00019 \\
\hline
\end{tabular}

quitoes agree with empirical studies demonstrating that rearing temperatures affect life history parameters such as mortality, growth and development rate. All the strains reduced in size at the highest developmental temperature. This has been observed previously with Drosophila, Aedes, and other insects (Tantawy \& Mallah, 1961; Van den Heuvel, 1963; Atkinson, 1994; Imasheva et al., 1997), which is the expectation in most ectotherms.

Reduction in female body weight is likely to impact on fecundity, since the two are linked in Diptera (Lyimo \& Takken, 1993; Xue \& Ali, 1994). However, higher developmental temperatures stimulate faster development, which could counterbalance any negative effects that reduced fecundity might have on fitness (Sibly, 1989; Holloway et al., 1990; Povey \& Holloway, 1992). A reduction in fitness ultimately indicates whether an organism is stressed. In this study, neither changes in body weight nor development period can be taken definitely as indications of stress. However, increase in juvenile mortality probably does indicate stress as no correlated positive changes in any other characters occurred which may have counteracted the negative effects of increased mortality on fitness. Between $25^{\circ} \mathrm{C}$ and $30^{\circ} \mathrm{C}$ juvenile mortality only increased in S-LAB. Mortality increased in all three strains at $37^{\circ} \mathrm{C}$, indicating that the design followed here induced increasing temperature stress in the experimental animals.

Temperature stress has been reported to produce increased levels of asymmetry in various insect species (McKenzie \& Yen, 1995; Freebairn et al., 1996; Imasheva et al., 1997), although this finding is not universal (Brakefield \& Breuker, 1996; Bjorksten et al., 2001). Fluctuating asymmetry of female WL increased with increasing temperature in all the strains used here. Asymmetry in the two laboratory strains was higher than in KOTTA. In males, generally temperature did not induce significantly increased levels of FA. The only exceptions to this were with D8, with significance at around the 5\% level. These sex differences could be due to differences in physiology or possibly differing selective forces operating to maintain wing symmetry in males and females. Mosquitoes mate on the wing (Downes, 1969; Charlwood \& Jones, 1979). Consequently, precision flight is required, especially for males which swarm and compete to mate with incoming females. Increased levels of wing FA may interfere with flight performance and reduce competitive ability in males. Therefore, stabilising selection to reduce wing asymmetry may be more intense in males than females.

The laboratory strains S-LAB and TEMIX were very closely related and shared a common genetic background. However, TEMIX had been selected with insecticide and the $\mathrm{LC}_{50}$ of TEMIX to temephos was 224-fold higher than for S-LAB. Resistance in this strain is due to the overexpression of the B1 carboxylesterase following amplification of the structural gene (Mouchès et al., 1986). Fitness costs associated with this gene have been reported previously, although the comparisons have been made using strains that did not share a common genetic background (Ferrari \& Georghiou, 1981; El-Khatib \& Georghiou, 1985). In this study, the B1 gene had been crossed and repeatedly backcrossed into $S-L A B$ to produce the TEMIX strain (with amplified B1). Although TEMIX had a reduced survivorship at $25^{\circ} \mathrm{C}$ and smaller adults at $37^{\circ} \mathrm{C}$ compared to the S-LAB strain, if anything, the levels of asymmetry were higher in the susceptible strain. This finding is at odds with arguments previously forwarded that insecticide resistance genes disrupt the developmental stability of the organism (McKenzie \& Clarke, 1988; Batterham et al., 1996; Freebairn et al., 1996).

The resistant field strain KOTTA had smaller adults than SLAB, but survivorship was higher than in either lab strain (Table 1). Also KOTTA displayed the lowest level of fluctuating asymmetry in both sexes at all temperatures 
(Fig. 2). There is little evidence that the presence of resistance genes in KOTTA (amplified A2B2 carboxylesterase genes) had any negative effect on developmental stability as might be indicated through increased FA.

One reason why FA was higher in laboratory strains compared to the field strain could be due to variation in selection pressure between the laboratory and the field environments. Developmental selection against less fit gametes and offspring is not a new concept (Buchholz, 1922). However, Møller (1997) extended it to include selection against developmentally unstable offspring. Field conditions are usually harsh and organisms are exposed to a multitude of stresses such as competition, parasites, pathogens, predators, physico-chemical conditions, temperature fluctuations and so forth (Hardersen et al., 1999). Selective pressures remove less fit individuals from populations. In comparison, laboratory conditions may be relatively benign and because of relaxed selection, such individuals might survive to adulthood. It is therefore possible that the laboratory populations contain individuals that are generally less fit and hence more asymmetric than those in the field.

In a previous study, wing asymmetry in S-LAB did not increase with increasing density, even though density was demonstrated to be extremely stressful (Mpho et al., 2000). Suggestions for this lack of correlation included canalisation of wing traits, inbreeding levels being too high to elicit a further response and mortality removing all of the developmentally unstable individuals (Mpho et al., 2000; Mpho 2000). Despite the results of Mpho et al. (2000), this study has demonstrated that it might be possible to use wing FA to monitor environmental stress using, for example, female WL. Both the highest and lowest levels of FA10 found by Mpho et al. (2000) were within the FA10 range found in the present study. High levels of mortality were found at the highest temperatures. If all developmentally unstable individuals were selectively removed prior to emergence, an association between FA and stress level would not exist. Given the results, the reasons for a lack of correlation between FA and density stress (Mpho et al., 2000) remain unclear.

Another important finding by Mpho et al. (2002) was that there was very little genetic variation for FA in wing characters. This is important because any FA found must reflect variations in environmental quality rather than genetic variation among different groups of animals for FA to stand any chance of serving as a biomarker. The use of FA as a biomarker of environmental stress has great appeal because of its simplicity and cost. The findings of the present study, along with those of Mpho et al. (2000, 2001, 2002) suggest that it might be possible to use FA in Culex mosquitoes as such a biomarker under certain conditions. The type of stress to which the animals are exposed and the sex used to measure FA may influence whether a relationship is found. For example, the results of the current study suggest that female FA is more responsive to some of the stressors used here, whilst Mpho et al. (2001) found evidence that male FA responded to chemical stress, in the form of organophos- phate insecticide, more than female FA. The picture remains unclear and more work needs to be carried out to establish whether there are particular conditions required to produce repeatable results and whether these results relate to just one sex.

ACKNOWLEDGEMENTS. We are very grateful to Phil Wilson for technical help with the image analysis and to two anonymous referees for constructive criticism of an earlier version of the manuscript. M. Mpho was supported by the University of Botswana. The image analysis equipment was purchased on NERC grant GR3/9463.

\section{REFERENCES}

Аввотт W.S. 1925: A method of computing the effectiveness of an insecticide. J. Econ. Entomol. 18: 265-267.

AllendDorF F.W. \& Leary R.F. 1986: Heterozygosity and fitness in natural populations of animals. In: Soulé M.E. (ed.) Conservation Biology: The Science of Scarcity and Diversity. Sinauer Association Inc., Sunderland, MA, pp. 57-76.

ANDERSON W.W. 1973: Genetic divergence in body size among experimental populations of Drosophila pseudoobscura kept at different temperature. Evolution 27: 278-284.

AtKInson D. 1994: Temperature and organism size - A biological law for ecotherms? Adv. Ecol. Res. 25: 1-58.

AtKInson D. \& Sibly R.M. 1997: Why are organisms usually bigger in colder environments? Making sense of a life history puzzle. TREE 12: 235-239.

Batterham P., Davies A.G., Game A.Y. \& McKenzie J.A. 1996: Asymmetry - where evolutionary and developmental genetics meet. Bioessays 18: 841-845.

Bjorksten T., David P., Pomienkowski A. \& Fowler K. 2000: Fluctuating asymmetry as sexual and nonsexual traits in stalkeyed flies: a poor indicator od developmental stress and genetic quality. J. Evol. Biol. 13: 89-97.

Bjorksten T.A., Pomienkowski A. \& Fowler K. 2001: Temperature shock during development fails to increase the fluctuating asymmetry of a sexual trait in stalk-eyed flies. Proc. Roy. Soc. Lond. B 268: 1503-1510.

BraKeFIELd P.M. \& BREUKER C.J. 1996. The genetical basis of fluctuating asymmetry for developmentally integrated traits in a butterfly eyespot pattern. Proc. Roy. Soc. Lond. B 263: $1557-1563$.

BuchHolz J.T. 1922: Developmental selection in vascular plants. Bot. Gaz. 73: 249-286.

CHARLwood J.D. \& Jones M.D.R. 1979: Mating in the mosquito, Anopheles gambiae s.l. I. Close range and contact behaviour. Physiol. Entomol. 4: 111-120.

Cuany A., Handani J., Berge J., Fournier D., Raymond M., Georghiou G.P. \& Pasteur N. 1993: Action of esterase B1 on chlorpyrifos in organophosphate-resistant Culex mosquitoes. Pest. Biochem. Physiol. 45: 1-6.

David P., Hingle A., Fowler K. \& Pomienkowski A. 1999: Measurement bias and fluctuating asymmetry estimates. Anim. Behav. 57: 251-253.

Dobrin M. \& Corkum L.D. 1999: Can fluctuating asymmetry in adult burrowing mayflies (Hexagenia rigida, Ephemeroptera) be used as a measure of contaminant stress? J. Great Lakes Res. 25: 339-346

DOWNES J.A. 1969: The swarming and mating flight of Diptera. Annu. Rev. Entomol. 14: 271-298.

El-Khatri Z.I. \& Georghiou G.P. 1985: Comparative fitness of temephos-resistant, -susceptible, and hybrid phenotypes of southern house mosquito (Diptera: Culicidae). J. Econ. Entomol. 78: 1023-1029. 
Ferrari J.A. \& Georghiou G.P. 1981: Effect of insecticidal selection and treatment on reproductive potential of resistant, susceptible and heterogenous strains of the southen house mosquito. J. Econ. Entomol. 74: 323-327.

FinNey D.J. 1971: Probit Analysis. 3rd edn. Cambridge University Press, Cambridge, 333 pp.

FloAte K.D. \& Fox A.S. 2000: Flies under stress: a test of fluctuating asymmetry as a biomonitor of environmental quality. Ecol. Appl. 10: 1541-1550.

Fowler K. \& WhitLock M.C. 1994: Fluctuating asymmetry does not increase with moderate inbreeding in Drosophila melanogaster. Heredity 73: 373-376.

Freebairn K., Yen J.L. \& McKenzie J.A. 1996: Environmental and genetic effects on the asymmetry phenotype: Diazinon resistance in the Australian sheep blowfly, Lucilia cuprina. Genetics 144: 229-239.

Georghiou G.P., Ariaratnam V., Pasternak M.E. \& Lin C.S 1975: Organophosphorus multi-resistance in Culex pipiens quinquefasciatus in California. $J$. Econ. Entomol. 68: 461-467.

Georghiou G.P., Metcalf R.L. \& Gidden F.E. 1966: Carbamate resistance in mosquitoes: selection of Culex pipiens fatigans Wied. for resistance to Baygon. Bull. WHO 35: 691-708.

Gulllemald T., Makate N., Raymond M., Hirst B. \& CalLAGHAN A. 1997: Esterase gene amplification in Culex pipiens (Diptera: Simuliidae). Insect Mol. Biol. 6: 319-327.

Hardersen S., Wratten S.D. \& Frampton C.M. 1999: Does carbaryl increase fluctuating asymmetry in damselflies under field conditions? A mesocosm experiment with Xanthocnemis Zealandica (Odonata: Zygoptera). J. Appl. Ecol. 36: 534-543.

Hoffmann A.A. \& Parsons P.A. 1997: Extreme Environmental Change and Evolution. Cambridge University Press, Cambridge, $259 \mathrm{pp}$.

Holloway G.J., Povey S.R. \& Sibly R.M. 1990: The effect of new environment on adapted architecture. Heredity 64: $323-330$.

Hunt J. \& Simmons L.W. 1997: Patterns of fluctuating asymmetry in beetle horns: an experimental examination of the honest signaling hypothesis. Behav. Ecol. Sociobiol. 41: 109-114.

Imasheva A.G., Loeschcke V., Zhrvotovsky L.A. \& Lazebny O.E. 1997: Effects of extreme temperatures on phenotypic variation and developmental stability in Drosophila melanogaster and Drosophila buzzatii. Biol. J. Linn. Soc. 61:117-126.

LANG C.A. 1963: The effect of temperature on the growth and chemical composition of the mosquito. J. Insect Physiol. 9 : 279-286.

LYIMO E.O. \& TAKKEN W. 1993: Effects of adult body size on fecundity and the pre-gravid rate of Anopheles gambiae females in Tanzania. Med. Vet. Entomol. 7: 328-32.

MARKow T.A. 1995: Evolutionary ecology and developmental stability. Annu. Rev. Entomol. 40: 105-120.

McKenzIE J.A. 1996: Ecological and Evolutionary Aspects of Insecticide Resistance. R.G Landes Company \& Academic Press, Austin, Texas, U.S.A, 185 pp.

McKenzie J.A. \& Batterham P. 1994: The genetic, molecular and phenotypic consequences of selection for insecticide resistance. TREE 9: 166-169.

McKenzie J.A. \& Clarke G.M. 1988: Diazinon resistance, fluctuating asymmetry and fitness in the Australian sheep blowfly, Lucilia cuprina. Genetics 120: 213-220.

McKenzie J.A. \& Yen J.L. 1995: Genotype environment and the asymmetry phenotype. Dieldrin resistance in Lucilia cuprina (the Australian sheep blowfly). Heredity 75: 181-187.
Møller A.P. 1992: Parasites differentially increase fluctuating asymmetry in secondary sexual characteristics. J. Evol. Biol. 5: 691-699.

MølleR A.P. 1997: Developmental selection against developmentally unstable offspring and sexual selection. $J$. Theoret. Biol. 185: 15-422.

Mouchès C., Pasteur N., Bergé J.B., Hyrien O., Raymond M., De Saint Vincent B.R., De Silvesti M. \& Georghiou G.P. 1986: Amplification of an esterase gene is responsible for insecticide resistance in California Culex mosquito. Science 233: $778-780$.

Mрно M. 2000: Fluctuating Wing Asymmetry and Environmental Stress in Culex pipiens Complex Mosquitoes. PhD thesis. The University of Reading.

Mpho M., Holloway G.J. \& Callaghan A. 2000: Fluctuating wing asymmetry and larval density stress in Culex quinquefasciatus Say (Diptera: Culicidae). Bull. Entomol. Res. 90: 279-283.

Mpho M., Holloway G.J \&. Callaghan A. 2001: A comparison of the effects of organophosphate insecticide exposure and temperature stress on fluctuating asymmetry and life history traits in Culex quinquefasciatus. Chemosphere 45: 713-720.

Mpho M., Callaghan A. \& Holloway G.J. 2002: Temperature and genotypic effects on life history and fluctuating asymmetry in a field strain of Culex pipiens. Heredity $\mathbf{8 8}$ : 307-312.

PAlmer R.A. 1994: Fluctuating asymmetry analysis: A primer. In: Markow T.A., (ed.) Developmental Instability, its Origins and Evolutionary Implications. Kluwer, Dordrecht, The Netherlands, pp. 335-364.

Palmer R.A. \& Strobeck C. 1986: Fluctuating asymmetry: measurement, analysis, patterns. Annu. Rev. Ecol. Syst. 17: 391-421.

Parsons P.A. 1989: Environmental stresses and conservation of natural populations. Annu. Rev. Ecol. Syst. 20: 29-49.

Parsons P.A. 1990: Fluctuating asymmetry: An epigenetic measure of stress. Biol. Rev. 65: 131-145.

Pasteur N. \& Georghiou G.P. 1989: Improved filter paper test for detecting and quantifying increased esterase activity in organophosphate-resistant mosquitoes (Diptera: Culicidae). $J$. Econ. Entomol. 82: 347-353.

Povey S.R. \& Holloway G.J. 1992: The effect of energy tradeoffs on life history and fitness in the rice weevil, Sitophilus oryzae. Oikos 64: 441-450.

RABITSCH W.B. 1997: Levels of asymmetry in Formica pratensis Retz (Hymenoptera, Insecta) from a chronic metalcontaminated site. Environ. Toxic. Chem. 16: 1433-1440.

Savage A. \& Hogarth P.J. 1999: An analysis of temperatureinduced fluctuating asymmetry in Asellus aquaticus. Hydrobiologia 411: 139-143.

SHERIDAN L. \& POMIANKowsKI A. 1997: Fluctuating asymmetry, spot asymmetry and inbreeding depression in the sexual coloration of male guppy fish. Heredity 79: 515-523.

SiBLY R.M. 1989: What evolution maximizes. Funct. Ecol. 3: 129-135.

Sibly R.M. \& ATKrnson D. 1994: How rearing temperature affects optimal adult size in ectotherms. Funct. Ecol. 8: 486-493.

Swaddle J.P., Witter M.S. \& CUthill I.C. 1994: The analysis of fluctuating asymmetry. Anim. Beha. 48: 986-989.

TANTAWY A.O. \& MALLAH G.S. 1961: Studies on natural populations of Drosophila. 1. Heat resistance and geographical variation in Drosophila melanogaster and D. simulans. Evolution 15: 1-14. 
VAN VAlEN L. 1962: A study of fluctuating asymmetry. Evolution 16: $125-142$.

VAN DEN HEUVEL M.J. 1963: The effect of rearing temperature on the wing length, thorax length, leg length and ovariole number of the adult mosquito, Aedes aegypti (L.). Phil. Trans. R. Soc. Lond. B 115: 197-216.
Woods R.E., Hercus M.J. \& Hoffmann A.A. 1998: Estimating the heritability of fluctuating asymmetry in field Drosophila. Evolution 52: 816-824.

XUE R.D. \& Alı A. 1994: Relationship between wing length and fecundity of a pestiferous midge, Glyptotendipes paripes (Diptera: Chironomidae). J. Amer. Mosquito Control Assoc. 10: $29-34$.

Received January 25, 2002; revised August 26, 2002; accepted September 3, 2002 